\title{
Editorial - La relevancia de la Investigación
}

Les presento con placer la edición número 19 de la revista Memoria de Investigaciones en Ingeniería, que se ha venido publicando de manera sostenida desde el año 2000. Este año ha sido un año atípico, distinto, lleno de desafíos para cada uno de nosotros y también lo fue para Memoria. Desde sus comienzos, la revista ha tenido un crecimiento sostenido en cada una de las ediciones anuales. Este año nos planteamos el desafío de tener dos ediciones anuales. Al principio, pareció difícil, arriesgado, pero al igual que la sociedad logró unirse para enfrentar los cambios que hemos experimentado en estos tiempos de caos, el esfuerzo de los autores, revisores y del consejo editorial lo hicieron posible.

La pandemia ocasionada por el COVID-19 ha generado muchos efectos negativos, por el número de fallecidos a nivel mundial, así como la pérdida de trabajo y cierre de muchas empresas. Pero también, ha mostrado varios efectos positivos, algunos de ellos destacados en los medios nacionales e internacionales, como la importancia y relevancia de la investigación científica para el desarrollo de la sociedad. Se ha demostrado el valor de los investigadores, en distintas áreas del saber, que mediante su trabajo diario y en algunos casos honorario, han ayudado a superar de la mejor manera posible esta pandemia. También la pandemia nos ha hecho reflexionar que las principales causas de contagio (y que debemos evitar en esta etapa) radican en aquellos actos simples e importantes de nuestra vida, y como sin ellos se nos dificulta ser plenamente humano. Un abrazo, juntarse con amigos, festejar la Navidad rodeada de toda la familia extendida, poder trabajar en conjunto con el equipo, asistir a actividades culturales y espirituales. Todo esto es lo que debemos evitar pero que ansiamos volver a realizar. Es momento de valorar las acciones cotidianas del día a día.

A su vez, este año la Facultad de Ingeniería con el deseo de seguir creciendo ha firmado un acuerdo con el parque tecnológico LATU para mudar sus instalaciones e instalarse en el predio. El LATU está integrado por una comunidad de empresas y organizaciones tanto públicas y privadas vinculadas a la tecnología, la educación, el emprendedurismo, la innovación y la investigación. Esto permitirá fortalecer la relación y trabajo de la Facultad con las empresas que día a día lleva a cabo.

En esta edición de la revista Memoria de Investigaciones en Ingeniería se combinan trabajos tan variados como el desarrollo de un prototipo que permite identificar señalamientos en entornos abiertos para la orientación de personas con discapacidad visual hasta un modelo de decisión para determinar fuentes de retorno, incentivos y capacidad en un sistema de remanufactura. A su vez, se tratan temas relacionados a la eficiencia energética y la valorización y prevención de residuos en empresas de servicios.

Por último, quisiera agradecer y destacar que esta edición es fruto del esfuerzo y dedicación de Rodrigo Sanchez quién lanzó la convocatoria y fue encargado de la edición y comunicación con los autores, y del apoyo de la Lic. Valentina Morandi quien brindó los servicios de biblioteca de la Universidad de Montevideo. Por primera vez, hemos podido ingresar la revista en el catálogo 2.0 de Latindex.

\author{
Martin Tanco, $\mathrm{PhD}$. \\ Director Editor \\ Facultad de Ingeniería \\ Universidad de Montevideo
}

Memoria Investigaciones en Ingeniería, núm. 19 (2020)

https://doi.org/10.36561/ING.19.1

ISSN 2301-1092 • ISSN (en línea) 2301-1106 